\title{
TCOM \\ Engaging migrant and refugee communities in non-formal science learning spaces
}

\section{Reviewed Conference}

Reviewed by

Abstract

Keywords

DOI

\author{
PISEA INTERNATIONAL SYMPOSIUM, \\ VienNa, AUSTRIA, 17-18 OCTOBER 2019
}

\section{Autumn Brown, Joseph Roche and Mairéad Hurley}

In this era of pandemics, economic crises and civil unrest, science centres and museums have an opportunity to become truly relevant resources to society. This paper summarises a number of critical lessons from the PISEA International Symposium, a conference held the at the Austrian Museum of Folk Life and Folk Art in Vienna from the $17^{\text {th }}-18^{\text {th }}$ of October 2019. The purpose of this event was to share, learn, and discuss ways in which engagement with migrants and refugee populations might be improved within informal science learning spaces. Issues around integration, inclusive art-science practice, and shifting institutional policy and language were all explored. This paper also calls for the committed reform of informal science spaces, and a renewed commitment to responsive, equitable, and inclusive practice.

Public engagement with science and technology; Science centres and museums; Social inclusion

https://doi.org/10.22323/2.19040601

Submitted: 19th June 2020

Accepted: 7th July 2020

Published: 20th July 2020

PISEA (Promoting Intercultural Science Education for Adults) is an international partnership funded by Erasmus+. The group disseminates tools for informal science education institutions to strengthen intercultural competencies and offer science learning activities which meet the needs of refugees and migrants [PISEA project, 2019]. The initiative was created in response to the ongoing global refugee crisis [de Vries, Carrera and Guild, 2016; Blockmans, 2016; Crawley and Skleparis, 2017; Iacobucci, 2020]. Cultural and educational institutions have a unique opportunity to hold space for intercultural dialogues between migrants, refugees, and host societies.

They have the power to become vital integrative resources to migrant groups [Kofman, 2019; de Vries and Guild, 2019] and provide low-threshold adult science 
education and responsive learning support to meet the needs of asylum seekers [Bodo, 2007; Lannes and Monsein Rhodes, 2019; Westerman, 2017].

The PISEA International Symposium was held from the $17^{\text {th }}-18^{\text {th }}$ of October 2019. Hosted by the Verein ScienceCenter-Netzwerk, [Verein Science Center-Netzwerk, 2019] the event was held at the Austrian Museum of Folk Life and Folk Art in Vienna [Johler, 2008]. Attendees included researchers, museum and science centre staff, educators, policy makers, and artists from across the globe. The purpose of the conference was to learn, share, and discuss ways in which engagement with migrants and refugee populations might be improved within informal science learning spaces. The PISEA consortium also shared a comprehensive toolkit ${ }^{1}$ for science education institutions. This was shared alongside practical workshops, facilitated experimentations, guided reflections, and an expansive tour of a science learning space called the Knowledge Room ${ }^{2}$ [Streicher, Unterleitner and Schulze, 2014] designed to meet the needs of migrant and refugee communities in Vienna.

Uncertainties and the issue of integration
During the first panel session, Teresa Albano, of the Organization for Security and Co-operation in Europe, explained that there is no international definition of migration. Although a shared definition of a migrant worker exists, "Foreigners admitted by the receiving State for the specific purpose of exercising an economic activity remunerated from within the receiving country" [United Nations, 2019]. Words such as migrant and refugee are often used interchangeably, and do not have a widely accepted, policy-based definition. This lack of consensus was echoed throughout the conference, and questions arose of how researchers, policy makers, educators, and other stakeholders may address an issue whose parameters and descriptions have yet to be defined. How can we discuss something that we struggle to describe?

Another recurring issue was the practice of integration. Christopher Omann of KOMPA Caritas [Caritas Wien, 2011], an organisation which uses participatory methods to facilitate meaningful dialogue between local community members and refugees within Austria, shared his perspective, "Our goal is to help refugees and migrants integrate through the use of events which fall under three main categories: knowledge transfer, shared new experiences, and conflict mediation." Omann and others were cautious to advocate not for direct assimilation, but integration. These were experiences in which perspectives, both local and international, were given equal value and credibility.

Oana Timofte of the International Organization for Migration [Andrijasevic and Walters, 2010] described meaningful integration as a two-way process, which must acknowledge the needs, values, challenges, and contributions of both local and migrant communities. She went on to explain that "Work is required from both sides, [they] must be willing, politically and socially, to put the effort into expanding their community." Here Timofte highlights a crucial point, that impactful research and policy work pertaining to the experience of refugees must also directly address the needs and attitudes of the local community.

\footnotetext{
${ }^{1}$ Available for download at http:/ / pisea.eu.

${ }^{2}$ More information available at https://www.science-center-net.at/type-projekte/wissensraum-english/.
} 


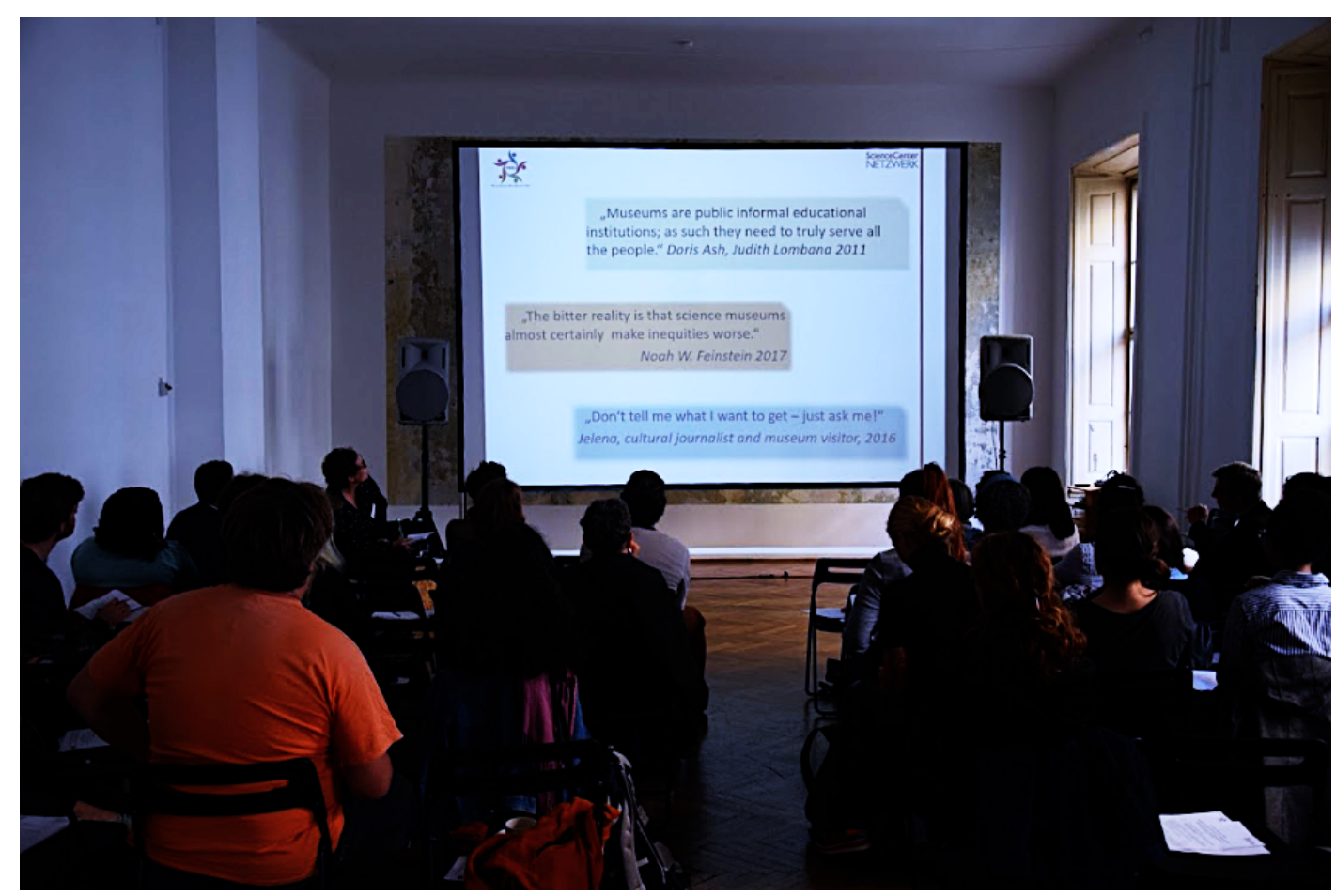

Figure 1. ScienceCenter-Network, Austria. A presentation on inclusivity within cultural spaces. (c) ScienceCenter-Network, Austria.

The practical ways in which non-formal science learning spaces may become more inclusive
A number of speakers underscored the importance of rethinking education in a non-formal context through active listening. One of the core strengths of informal contexts is that success is defined by the learner [Struminger et al., 2018]. As one participant said, “... Do not expect people to show up and immediately accept someone else's expectations and definitions of success." Practitioners should be explicit in their support of the knowledge and enrichment goals set by the learner.

A shift in institutional language may also be helpful. Instead of asking for acceptance or compromise, highlight the advantages of learning from and catering to a wider range of experiences and perspectives. Diverse communities result in an increase of human and cultural capital for all involved. Words such as inclusion or integration highlight the differences, creating a feeling of "us and them". Speaking about the mutual benefits of working and living with people from other nations helps facilitate openness. Diversity is now a structural feature of modern society, and so we must re-examine our own individual and national identities accordingly.

Céline Martineau of the group TRACES, ${ }^{3}$ an emancipatory science communication organization in France, explained that when dissimilar groups shared a common goal they were able to better navigate their differences. She says, "We had our learners switching roles of teacher and learner... [and complete] game-like tasks which helped them better communicate with each other." Instead of focusing on the individual they are working with, participants are set a common goal, and are able to recognise, value, and utilise a different participatory perspective [Ash, 2004]. Switching roles may also serve to mitigate the impacts of assumed power structures between participants, creating opportunities for all learners to take a leadership role.

\footnotetext{
${ }^{3}$ Learn more at https://www.groupe-traces.fr/en/.
} 
The role of art in facilitating equitable science learning
A number of speakers described their use of art in creating equitable science engagement opportunities. In some cases, art allowed learners to transcend language barriers. One speaker noted, "Art brings different parties together and seems to facilitate a strong non-verbal understanding between people." As a shared resource, learners and educators were able to utilise artworks to better facilitate the discussion of complex natural and cultural phenomena.

There was also evidence to suggest that meeting in art spaces allowed learners to confront stereotypes in a symbolic arena and re-evaluate their identities as outsiders. As one participant shared, "We are talking about an experience that is shared... I am accessing this temple of culture which felt beyond me." Some of the initiatives provide access to "temples of culture" within a host country, such as art museums and science centres where groups of learners were encouraged to discuss, evaluate, question, and critique the ways in which ideas and values are shared. These excursions provided learners with an opportunity to take ownership of cultural knowledge and to discuss topics such as art and science as tools of culture with long-time residents of the host community. This approach may allow migrants and refugees not only to question and explore host communities through a new avenue of inquiry, but to share their own knowledge and experiences comparatively through a variety of mediums [Bleiker, Campbell and Hutchison, 2014].

The location of the conference at the Austrian Museum of Folk Life and Folk Art in Vienna was of provided a prime example of the power of art and artefacts to reshape narratives and dialogues between communities. Recently, a number of curators, all refugees themselves, had the opportunity to restructure the exhibition material and contribute new work to the museum's collection. Conference attendees were offered a guided tour, conducted by these curators to highlight the impacts of a multicultural approach to storytelling, and the value of diverse perspectives. This portion of the conference served as a striking, and visceral reminder of the trauma, hardship and perseverance of these communities, and the absolute necessity of their experiential expertise in creating relevant, and deeply inclusive science learning opportunities. The low cost (€30), duration, ( 2 days), and the breadth and depth of material from a diverse group of researchers, practitioners, migrants and refugees provides ample reason to attend this conference.

In this era of pandemics, economic crises and civil unrest, science centres and museums have an opportunity to become truly relevant resources to society a potential we have yet to fulfill [Dawson and Streicher, 2020]. Now is the time to reevaluate our practices and priorities and deepen our connections with marginalised communities. It is the responsibility of all informal science institutions to provide robust science support to society [Canfield et al., 2020; Dawson, 2019; Orthia, 2020]. As migrant and refugee populations continue to rise throughout Europe [de Vries and Guild, 2019; Bodo, 2007; Lannes and Monsein Rhodes, 2019], centres of science education and engagement must become key resources for these marginalised populations while continuing to serve their traditional audiences. Now is the time to act and to commit ourselves to providing the vital and relevant support that all peoples, including migrants and refugees, deserve. This is the moment to act with humility and courage, to reform our approaches, and become cultural institutions which welcome, support, and value all communities. 


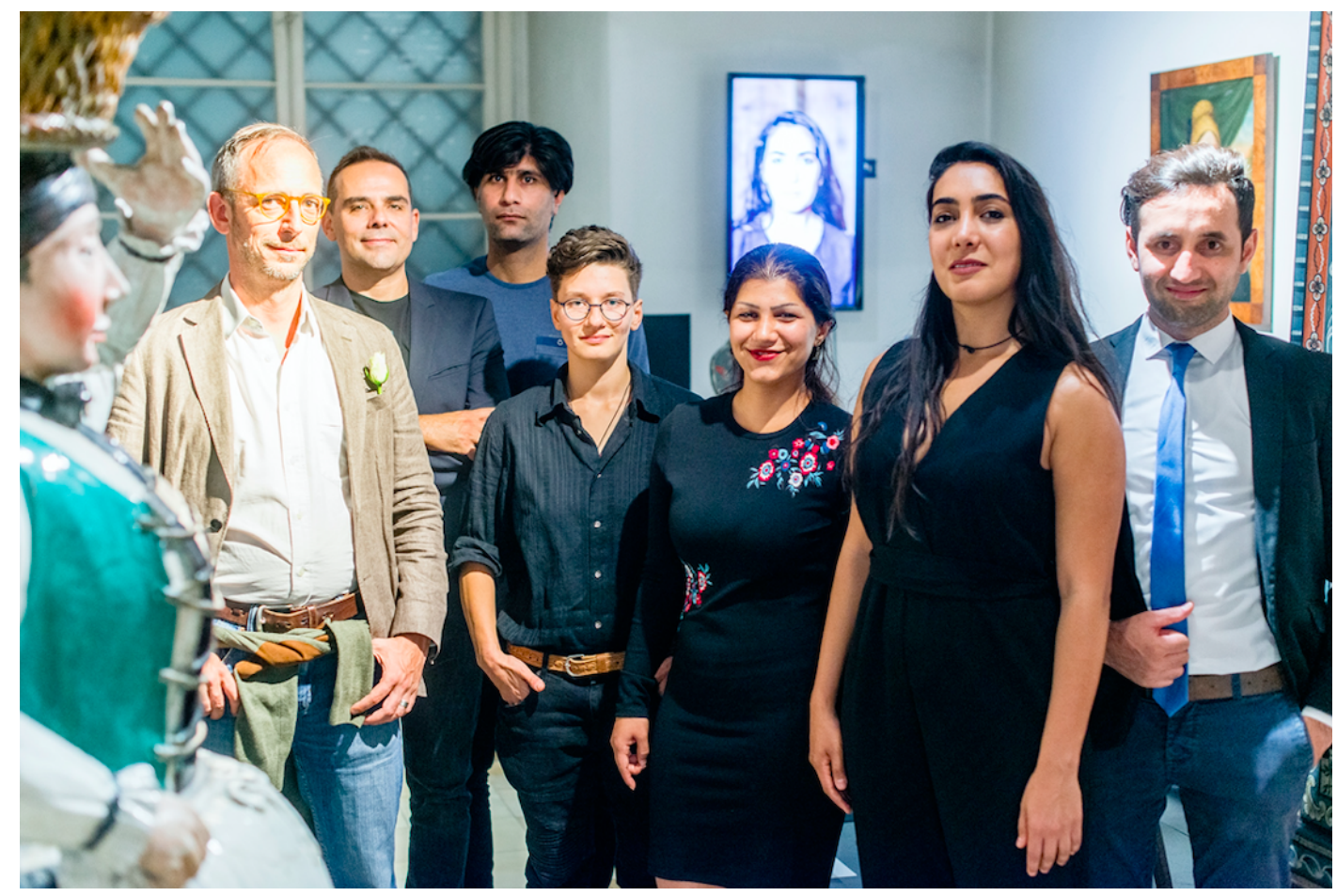

Figure 2. The curatorial team, left to right: Niko Wahl, Alexander Martos, Reza Zobeidi, Yarden Daher, Sama Yasseen, Negin Rezaie, Ramin Siawash. (c) Kramar/Volkskundemuseum Wien (2018).

\section{References}

Andrijasevic, R. and Walters, W. (2010). 'The international organization for migration and the international government of borders'. Environment and Planning D: Society and Space 28 (6), pp. 977-999. https://doi.org/10.1068/d1509.

Ash, D. (2004). 'Reflective scientific sense-making dialogue in two languages: the science in the dialogue and the dialogue in the science'. Science Education 88 (6), pp. 855-884. https://doi.org/10.1002/sce. 20002.

Bleiker, R., Campbell, D. and Hutchison, E. (2014). 'Visual cultures of inhospitality'. Peace Review 26 (2), pp. 192-200. https://doi.org/10.1080/10402659.2014.906884.

Blockmans, S. (2016). 'New Thrust for the CSDP from the Refugee and Migrant Crisis'. CEPS Special Report 142. URL: https://www. ceps . eu/ceps-publication s/new-thrust-csdp-refugee-and-migrant-crisis/.

Bodo, S. (2007). From heritage education with intercultural goals to intercultural heritage education: conceptual framework and policy approaches in museums across Europe. Paper commissioned by the ERICarts Institute.

Canfield, K. N., Menezes, S., Matsuda, S. B., Moore, A., Austin, A. N. M., Dewsbury, B. M., Feliú-Mójer, M. I., McDuffie, K. W. B., Moore, K., Reich, C. A., Smith, H. M. and Taylor, C. (2020). 'Science communication demands a critical approach that centers inclusion, equity and intersectionality'. Frontiers in Communication 5. https://doi.org/10.3389/f comm. 2020.00002.

Caritas Wien (2011). Caritas \& Du. KOMPA: Konfliktprävention, Mediation und Partizipation. URL: https://www. caritas-wien.at/hilfe-angebote/asyl-inte gration/miteinander/kompa/. 
Crawley, H. and Skleparis, D. (2017). 'Refugees, migrants, neither, both: categorical fetishism and the politics of bounding in Europe's 'migration crisis". Journal of Ethnic and Migration Studies 44 (1), pp. 48-64.

https://doi.org/10.1080/1369183x.2017.1348224.

Dawson, E. and Streicher, B. (2020). 'Responding to the pandemic: a social justice perspective'. Spokes: social justice 63.

URL: https://www.ecsite.eu/activities-and-services/news-and-publicat ions/digital-spokes/issue-63\#section=section-indepth\&href=/feature/d epth/responding-pandemic-social-justice-perspective.

Dawson, E. (2019). Equity, exclusion and everyday science learning: the experiences of minoritised groups. London, U.K.: Routledge.

de Vries, L. A., Carrera, S. and Guild, E. (2016). 'Documenting the Migration Crisis in the Mediterranean'. CEPS Paper in Liberty and Security in Europe 94.

URL: https://www. ceps .eu/ceps-publications/documenting-migration-cri sis-mediterranean-spaces-transit-migration-management-and/.

de Vries, L. A. and Guild, E. (2019). 'Seeking refuge in Europe: spaces of transit and the violence of migration management'. Journal of Ethnic and Migration Studies 45 (12), pp. 2156-2166. https://doi .org/10.1080/1369183x.2018.1468308.

Iacobucci, G. (2020). 'Covid-19: doctors warn of humanitarian catastrophe at Europe's largest refugee camp'. BMJ 368, m1097. https://doi.org/10.1136/bmj.m1097.

Johler, B. (2008). 'The Austrian Museum of Folk Life and Folk Art in times of political upheaval. Initial insight into a new Viennese history of the museum'. Osterreichische Zeitschrift für Volkskunde 111 (3), pp. 229-263.

Kofman, E. (2019). 'Gendered mobilities and vulnerabilities: refugee journeys to and in Europe'. Journal of Ethnic and Migration Studies 45 (12), pp. 2185-2199. https://doi.org/10.1080/1369183x.2018.1468330.

Lannes, P. and Monsein Rhodes, L. (2019). 'Museums as allies: mobilizing to address migration'. Journal of Museum Education 44 (1), pp. 4-12. https://doi.org/10.1080/10598650.2018.1563453.

Orthia, L. (2020). 'Strategies for including communication of non-Western and indigenous knowledges in science communication histories'. JCOM 19 (02), A02. https://doi.org/10.22323/2.19020202.

PISEA project (2019). PISEA: Promoting Intercultural Science Education for Adults. URL: http://pisea.ea.gr/pisea.

Streicher, B., Unterleitner, K. and Schulze, H. (2014). 'Knowledgeorooms - science communication in local, welcoming spaces to foster social inclusion'. JCOM 13 (02), C03. https://doi.org/10.22323/2.13020303.

Struminger, R., Zarestky, J., Shortw, R. A. and Lawing, A. M. (2018). 'A framework for informal STEM education outreach at field stations'. BioScience 68 (12), pp. 969-978. https://doi.org/10.1093/biosci/biy108.

United Nations (2019). Handbook on civil registration, vital statistics and identity management systems: communication for development. United Nations Statistics Division.

Verein Science Center-Netzwerk (2019). Verein Science Center-Netzwerk webpage. URL: https://www.science-center-net .at.

Westerman, W. (2017). 'Museums, refugees and collaborative social transformation'. In: Global mobilities: refugees, exiles and immigrants in museums and archives. Ed. by A. Levin. London, U.K.: Routledge, pp. 31-48. https://doi.org/10.4324/9781315695563. 
Autumn Brown is a Ph.D. researcher at Trinity College Dublin and first Ph.D. researcher based at Science Gallery Dublin. Her work explores the impacts of art-science approaches in informal public spaces and the ways in which these happenings may be used to transform the future of scientific research and technological innovation. Much of her research is concerned with issues of representation, equity and inclusion and methods which better capture and reflect the scientific and technological values of marginalised communities.

E-mail: autumn.brown@dublin.sciencegallery.com.

Joseph Roche is an astrophysicist and assistant professor in science education at Trinity College Dublin. He leads the Science \& Society research group and teaches science education and communication at undergraduate, masters, and doctoral levels. E-mail: Joseph.Roche@tcd.ie.

Mairéad Hurley is the Head of Research \& Learning at Science Gallery Dublin. She holds a Ph.D. in Astronomy and has experience in the formal education system as a teacher of science and mathematics. In her current role, she oversees the development of transdisciplinary art-science educational programmes at Science Gallery Dublin, and leads a team of researchers investigating the intersections of art and science in informal education settings. She is the Principal Investigator of the European Commission-funded project SySTEM 2020 which examines science learning outside the classroom in more than 20 countries across Europe. She joined the Ecsite Conference's Programme Committee as an expert in summer 2019. E-mail: mairead.hurley@dublin.sciencegallery.com.

\section{How to cite}

Brown, A., Roche, J. and Hurley, M. (2020). 'Engaging migrant and refugee communities in non-formal science learning spaces'. JCOM 19 (04), R01. https://doi.org/10.22323/2.19040601. 